\title{
COUPLING BETWEEN SEPARATE PHASES OF COAXIAL DOUBLE CIRCUIT TRANSMISSION LINES
}

\author{
M. HAMED \\ Faculty of Engineering, Suez Canal University, Port Said, Egypt
}

(Received October 14, 1987, in final form November 2, 1987)

The paper studies the so-called coaxial overhead transmission lines. The concentric phases are considered. The mathematical analysis for voltage and current is presented. The telegraphic equations of the double circuit power lines with the mutual effect between circuits are introduced. The condition for single circuit transmission line is checked. The mutual effect between both circuits is studied on the basis of the ratio between the two currents of both circuits. The appeared phase shift between the two vectors of currents is inserted in the investigation. The magnetic field intensity at an external point of a line is mathematically expressed. Its value is approximated for the purpose of zero mutual inductance between phases of the same circuit. The mutual inductance between the two nearest groups of phases due to the linkage flux for the studied line is formulated. Its dependency on the distance from the phases as well as on the ratio of currents of both circuits is analysed. Then, the effect of phase shift on the mutual inductance is investigated. An idea for the control of the ratio between currents of both circuits of a line is presented.

Key words: Coupling, mutual inductance, magnetic field, transmission, long lines, spacing, transposition, power, configuration, telegraphic equations.

\section{INTRODUCTION}

It has been pointed out that UHV transmission systems up to 1600 $\mathrm{kV}$ are technically feasible and environmental concerns would not be an obstacle to their construction. With the movement to these very high transmission voltages, some traditional relationships may be changed significantly ${ }^{1,2}$. For example, at voltages such as $220 \mathrm{kV}$ for transmission, the cost of both towers and insulators is approximately equivalent to the cost of the conductor system. Studies have showr that the electric strength of air gaps between phase bundles and 
ground structures or the ground conductor is increased with larger bundle radius or number of subconductors ${ }^{3,4}$. The situation will be different at UHV levels where crossarmless towers may cost as little as one third of the cost of conductor bundels. However, the UHV power transmission will make it possible to maximize the concentration of power transmissible over a given strip of land and, therefore, to minimize the occupation of land for power transmission purpose.

UHV transmission appears to offer particular advantages in those countries where large generation sites are located far from load centers. A very important factor in the future of UHV transmission, which has not been presented in the past, will be the need to move large blocks of energy over long distances. This problem is created due to the change in the world's fuel situation. An advantage would be to concentrate energy sources in a few areas particularly suitable for safety or environmental reasons to avoid constructing generation plants all over the territory.

Although it has been concluded that UHV DC transmission represents an alternative for very long distances $(1000-1500 \mathrm{~km}), \mathrm{AC}$ transmission remains the main tool for such a transmission ${ }^{1}$.

\section{PROBLEM FORMULATION}

The subject of power transmission over long distances has been studied $^{5-8}$ and different configurations for the conductors of phases of such long transmission lines have been tried ${ }^{5}$. The single line diagram for these suggested double circuit lines is given in Figure $1^{5}$. For exact results, the equivalent circuit for the given single line diagram of Figure 1 can be represented for an incremental distance $\mathrm{dx}$ as shown in Figure 2. The phases of the first circuit $\mathrm{A}, \mathrm{B}$ and $\mathrm{C}$

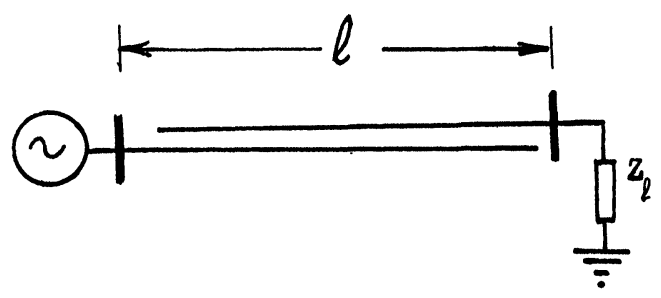

FIGURE 1 Single line diagram for the studied type of lines. 


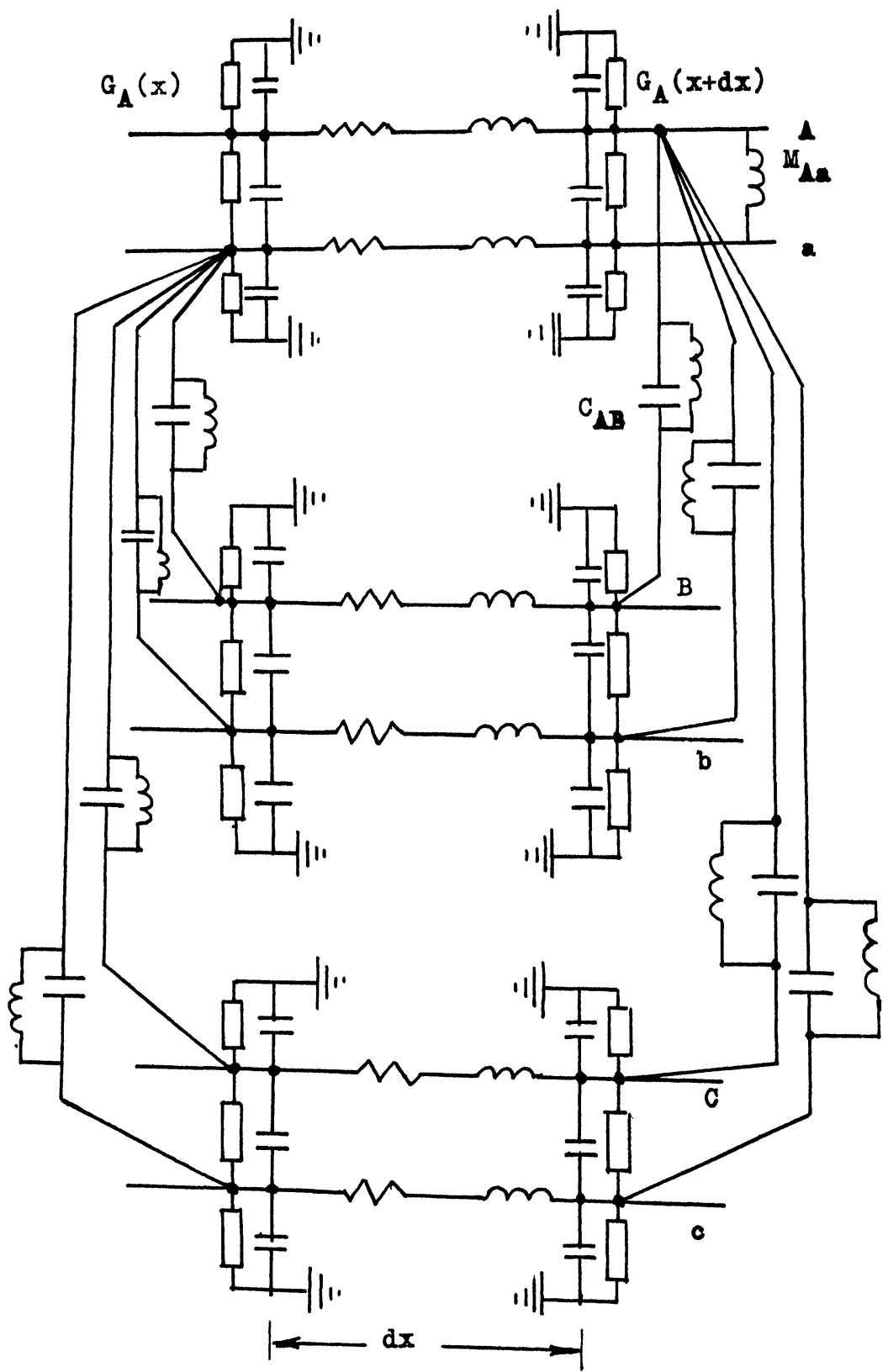

FIGURE 2 The equivalent circuit for a section $\mathrm{dx}$ of the proposed transmission line. 
are connected only to the generating end with an opened receiving end, while the phases of second circuit $\mathrm{a}, \mathrm{b}$ and $\mathrm{c}$ are connected to the load at the receiving end with an opened sending end. This concept can be summaried as the mutual effect between both circuits for each cosequent phases A-a, B-b and C-c. Also, the mutual capacitance $C_{n m}$ and the mutual inductance $M_{n m}$ between phases $n$ and $m$ must be accounted for.

\section{CONFIGURATIONS OF CONDUCTORS}

Since the mutual effect should be considered for power transmission, various arrangements for conductors of phases must be studied. Different distributions for conductors of both circuits are shown in Figure $3^{6}$. The spacing between phases of Figure 3, a may be large due to
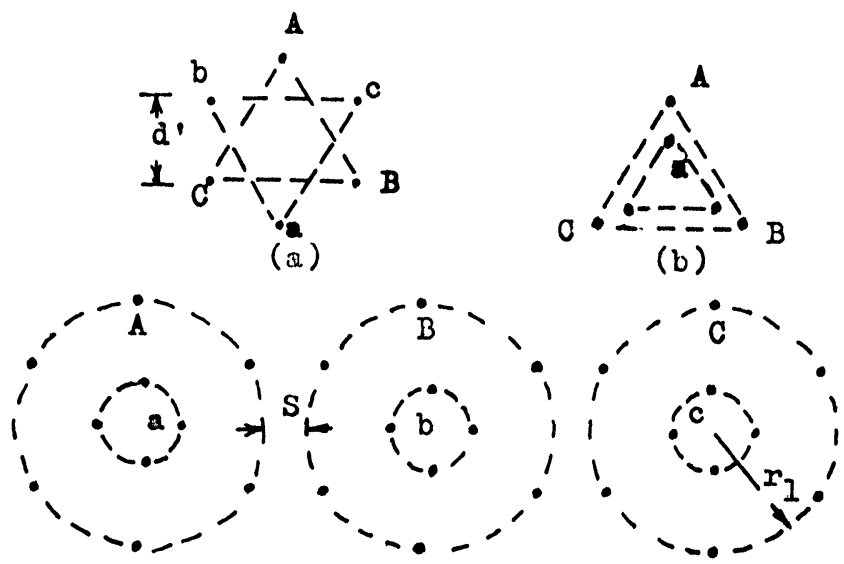

(c)

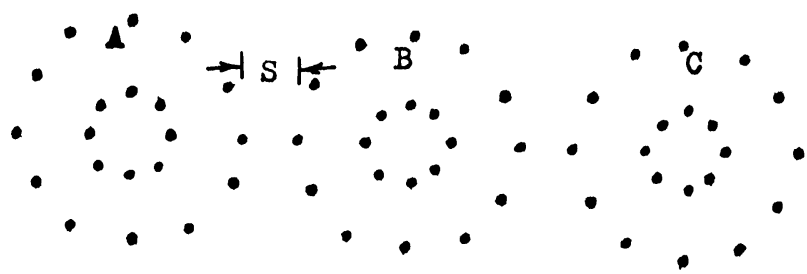

(d)

FIGURE 3 Different configurations for phases of the suggested type of transmission lines. 
the placement of all phases on the same circle. Another efficient arrangement with the given single line diagram of Figure 1 was proposed as shown in Figure 3,b while the best configuration for the conductors of phases appears to be the so-called coaxial arrangement of Figure $3, c^{5}$.This geometry may be modified in the present research in the form of Figure 3,d. This means an increase in the number of conductors per each phase so that each phase may be approximated in a cylinderical form. The inner phases will be $a, b$ and $c$ with $n_{2}$ conductors per phase in a circular shape. Also, the outer phases $A, B$ and $C$ will be located in a circle with $n_{1}$ conductors per phase.

\section{VOLTAGE AND CURRENT}

The telegraphic equations of a line for voltage $\mathrm{V}(\mathrm{x})$ and current $\mathrm{I}(\mathrm{x})$ at a distance $\mathrm{x}$ as a function of main parameters (resistance $\mathrm{R}$, inductance $\mathrm{L}$, conductance $\mathrm{G}$ and capacitance $\mathrm{C}$ ) may be expressed in the form ${ }^{9}$ :

$$
\begin{aligned}
-\mathrm{dV}_{\mathrm{n}}(\mathrm{x}) / \mathrm{dx}= & \left(R_{\mathrm{nn}}+j w L_{n n}\right) I_{n}(x)+\sum_{\substack{\mathrm{m}=1 \\
\mathrm{~m} \neq \mathrm{n}}}^{6} j w M_{n m} I_{m}(x) \\
-\mathrm{dI}_{\mathrm{n}}(\mathrm{x}) / \mathrm{dx}= & -\left(G_{\mathrm{nn}}+j w C_{n n}+\sum_{m=1}^{6}\left(G_{n m}+j w C_{n m}\right)\right) \cdot V_{n}(x) \\
& +\sum_{\substack{m=1 \\
m \neq n}}^{6}\left(G_{n m}+j w C_{n m}\right) V_{m}(x)
\end{aligned}
$$

where $w$ is the angular frequency.

For the simple ordinary single circuit transmission lines, these equations can be transformed into the form:

$$
\begin{aligned}
& \frac{\mathrm{d}^{2}}{\mathrm{dx}^{2}}[\mathrm{~V}(\mathrm{x})]=[\mathrm{Z}][\mathrm{Y}][\mathrm{V}(\mathrm{x})] \\
& \frac{\mathrm{d}^{2}}{\mathrm{dx}^{2}}[\mathrm{I}(\mathrm{x})]=[\mathrm{Y}][\mathrm{Z}][\mathrm{I}(\mathrm{x})]
\end{aligned}
$$


where the matrices of series impedance [Z] and shunt admittance [Y] may be defined as

$[\mathrm{Z}]=[\mathrm{R}+\mathrm{jwL}]$

$[Y]=[G+j w C]$

In these equations the mutual effect between circuits is absent.

It must be noted that the solution of equations (2) may be given in the general form 9 :

$[\mathrm{V}(\mathrm{x})]=[\cosh \mathrm{b}(1-\mathrm{x})][\mathrm{V}(\mathrm{l})]+\left[\mathrm{Z}_{\mathrm{c}}\right][\sinh \mathrm{b}(1-\mathrm{x})][\mathrm{I}(\mathrm{l})]$

$[\mathrm{I}(\mathrm{x})]=\left[\mathrm{Z}_{\mathrm{c}}\right]^{-1}[\sinh \mathrm{b}(1-\mathrm{x})][\mathrm{V}(\mathrm{l})]+[\cosh \mathrm{b}(1-\mathrm{x})][\mathrm{I}(\mathrm{l})]$

where $b$ - propagation coefficient

$\mathrm{V}(\mathrm{l})$ - the matrix of voltage at receiving end of a line

I(l) - the matrix of current at receiving end of a line

$\mathrm{Z}_{\mathrm{c}}$ - the matrix of characteristic impedance of a line

1 - the line length

Similarly, the general solution for the fundamental telegraphic equations (1) for the suggested double circuit transmission lines can be deduced. This process was explained in ${ }^{10}$ in detail (See Appendix). Then, the general expressions for voltage and current in both circuits of a line may be formulated as ${ }^{5}$ :

$V_{A}(x)=A_{1} \cosh b_{1} x+B_{1} \sinh b_{1} x+C_{1} \cosh b_{2} x+D_{1} \sinh b_{2} x$

$V_{a}(x)=A_{2} \cosh b_{1} x+B_{2} \sinh b_{1} x+C_{2} \cosh b_{2} x+D_{2} \sinh b_{2} x$

$I_{A}(x)=A_{3} \cosh b_{1} x+B_{3} \sinh b_{1} x+C_{3} \cosh b_{2} x+D_{3} \sinh b_{2} x$

$I_{a}(x)=A_{4} \cosh b_{1} x+B_{4} \sinh b_{1} x+C_{4} \cosh b_{2} x+D_{4} \sinh b_{2} x$

The integration constants $\mathrm{A}_{1,2,3,4}, \mathrm{~B}_{1,2,3,4}, \mathrm{C}_{1,2,3,4}$ and $\mathrm{D}_{1,2,3,4}$ can be determined in terms of current $\mathrm{I}(0)$ and voltage $\mathrm{V}(0)$ at the generating end for the line on the basis of terminal conditions ${ }^{5}$. If 
the mutual effect between the two circuits disappears, the deduced equations (4) will be the same of ordinary line ${ }^{9}$.

It can be seen that there are two propagation coefficients $b_{1}$ and $b_{2}$ as concluded previously ${ }^{5,6,10}$. Also, each circuit of a line is considered completely transposed. The propagation coefficients can be expressed as

$\mathrm{b}_{1}=V\left(\mathrm{u}_{1}+\mathrm{n}_{2}\right) / 2+V\left(\mathrm{u}_{1}-\mathrm{n}_{2}\right)^{2} / 4-\mathrm{n}_{1} \mathrm{u}_{2}$

$\mathrm{b}_{2}=V\left(\mathrm{u}_{1}+\mathrm{n}_{2}\right) / 2-V\left(\mathrm{u}_{1}-\mathrm{n}_{2}\right)^{2} / 4-\mathrm{n}_{1} \mathrm{u}_{2}$

where $\mathrm{u}_{1}=-\left(\mathrm{Z}_{1} \mathrm{y}_{1}+\mathrm{Z}_{1} \mathrm{y}_{12}\right)$

$\mathrm{u}_{2}=-\left(\mathrm{Z}_{2} \mathrm{y}_{2}+\mathrm{Z}_{2} \mathrm{y}_{12}\right)$

$\mathrm{n}_{1}=-\left(\mathrm{Z}_{1} \mathrm{y}_{12}+\mathrm{Z}_{12} \mathrm{y}_{2}\right)$

$\mathrm{n}_{2}=-\left(\mathrm{Z}_{2} \mathrm{y}_{12}+\mathrm{Z}_{12} \mathrm{y}_{1}\right)$

Hence, voltage $V_{1}$ current $I_{1}$ of the first circuit may be determined in the final form ${ }^{6}$ :

$$
\begin{aligned}
\mathrm{V}_{1}(\mathrm{x})= & \cosh \mathrm{b}_{1}(1-\mathrm{x}) \mathrm{V}_{1}(1)+\frac{\sinh \mathrm{b}_{1}(1-x)}{\mathrm{b}_{1} \mathrm{~m}_{1}} \mathrm{I}_{1}(1) \\
& +\cosh \mathrm{b}_{2}(1-\mathrm{x}) \mathrm{V}_{2}(1)+\frac{\sinh \mathrm{b}_{2}(1-x)}{\mathrm{b}_{2} \mathrm{~m}_{2}} \mathrm{I}_{2}(1) \\
\mathrm{I}_{1}(\mathrm{x}) \quad= & \mathrm{b}_{1} \mathrm{~m}_{1}\left(\sinh \mathrm{b}_{1}(1-\mathrm{x}) \mathrm{V}_{1}(1)+\frac{\cosh \mathrm{b}_{1}(1-\mathrm{x})}{\mathrm{b}_{1} \mathrm{~m}_{1}} \mathrm{I}_{1}(1)\right) \\
& +\mathrm{b}_{2} \mathrm{~m}_{2}\left(\sinh \mathrm{b}_{2}(1-\mathrm{x}) \mathrm{V}_{2}(1)+\frac{\cosh \mathrm{b}_{2}(1-\mathrm{x})}{\mathrm{b}_{2} \mathrm{~m}_{2}} \mathrm{I}_{2}(1)\right)
\end{aligned}
$$

where $\mathrm{m}_{1}=-1 / \mathrm{Z}_{1}-\mathrm{Z}_{12} \mathrm{f}_{1} / \mathrm{Z}_{1}$

$m_{2}=-1 / Z_{1}-Z_{12} f_{2} / Z_{1}$

$\mathrm{f}_{1}=\mathrm{Z}_{12}\left(1-\mathrm{q}_{1}\right) /\left(\mathrm{Z}_{1}^{2}-\mathrm{Z}_{12}^{2}\right)$

$f_{2}=Z_{12}\left(1-q_{2}\right) /\left(Z_{1}^{2}-Z_{12}^{2}\right)$

$\mathrm{q}_{1}=\left(\mathrm{b}_{1}^{4}-\mathrm{u}_{1}^{2}-\mathrm{n}_{1}^{2}\right) / 2 \mathrm{n}_{1} \mathrm{u}_{1}$

$\mathrm{q}_{2}=\left(\mathrm{b}_{2}^{4}-\mathrm{u}_{1}^{2}-\mathrm{n}_{1}^{2}\right) / 2 \mathrm{n}_{1} \mathrm{u}_{1}$

Similarly for the second circuit, the voltage $V_{2}$ as well as the current $\mathrm{I}_{2}$ can be expressed ${ }^{6}$. 
It can be seen that the general constants for such a line are highly depending on the fundamental parameters. Also, their values have been previously checked for various conditions ${ }^{5,6,10}$. The determined equations for voltage and current of the second circuit will become the same as that for the first circuit only if the mutual effect between both circuits is neglected.

\section{Mutual Effect}

For simplicity, the conductors of the inner phases $a, b$, and $c$ will be assumed as a single equivalent conductor with radius $r$ (Figure 4). The ratio between currents may be related by

$$
\dot{\mathrm{I}}_{\mathrm{a}} / \dot{\mathrm{I}}_{\mathrm{A}}=\mathrm{Ne}^{\mathrm{jQ}}
$$

where $\mathrm{N}$ is a scaler value for the ratio between the magnitudes of both currents and $\mathrm{Q}$ will be the phase shift between them. The magnitude of both currents at no load was calculated as given in Figure $5^{6}$. The ratio $\mathrm{N}$ is computed as shown in Figure 5. This means that the value $\mathrm{N}$ is distance dependent. On the other hand it was concluded that the angle $\mathrm{Q}$ is a constant along the line ${ }^{6}$.

In order to find the suitable spacing between phases of the given

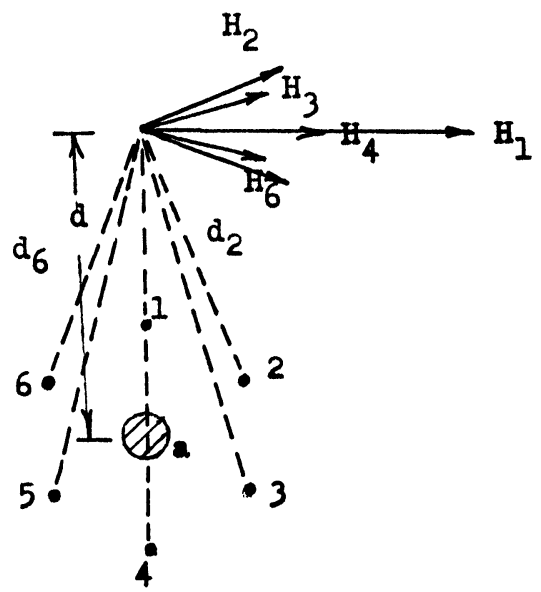

FIGURE 4 The study of mutual effect at a distance $d$ from the phase a. 


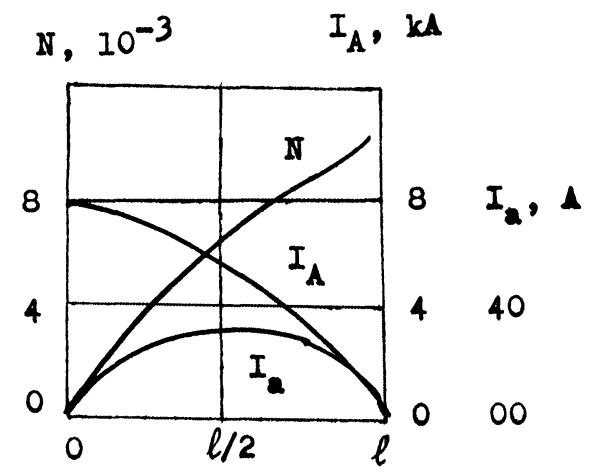

FIGURE 5 The distribution of current ratio along the line at a no load operation based on $\operatorname{ref}^{11}$.

coaxial transmission line, the magnetic field between each of the two respective phases should be estimated. Then at a point $F$, which is located at a distance $d$ from phase a as shown in Figure 4,a, the strength of magnetic field $\dot{\mathrm{H}}_{\mathrm{d}}$ may be evaluated by

$\dot{\mathrm{H}}_{\mathrm{d}}=\dot{\mathrm{H}}_{\mathrm{a}}+\sum_{\mathrm{i}=1}^{\mathrm{n}_{1}} \dot{\mathrm{H}}_{\mathrm{iA}}+\dot{\mathrm{H}}_{\mathrm{b}}+\sum_{\mathrm{i}=1}^{\mathrm{n}_{1}} \dot{\mathrm{H}}_{\mathrm{iB}}+\dot{\mathrm{H}}_{\mathrm{c}}+\sum_{\mathrm{i}=1}^{\mathrm{n}_{1}} \dot{\mathrm{H}}_{\mathrm{iC}}$

In this equation, the phases $a, b$, and $c$ are simulated by a solid conductor as given above. The mutual effect of phases $\mathrm{A}$ and a at point $\mathrm{F}$ must disappear in order to get the required suitable spacing.

As the total inductance between point $F$ and phases $A$ and a becomes zero, the mutual effect due to the other two groups of phases will also become zero. Therefore, only the first two terms of the right hand side of equation (7) could be considered for the next analysis. The total field intensity at a point $\mathrm{F}$ may be approximated as the deduced part of field $\dot{\mathrm{H}}$. This will be expressed mathematically by:

$\dot{\mathrm{H}}=\dot{\mathrm{H}}_{\mathrm{a}}+\sum_{\mathrm{i}=1}^{\mathrm{n}_{1}} \dot{\mathrm{H}}_{\mathrm{iA}}$

Also, it is known that the magnetic field intesity $\dot{\mathrm{H}}_{\mathrm{z}}$ at a point located at a distance $\mathrm{z}$ from the wire carrying capacity $\mathrm{I}$ can be 
expressed by ${ }^{11,12}$ :

$\dot{\mathrm{H}}_{\mathrm{z}}=\dot{\mathrm{I}} / 2 \pi \mathrm{z}$

This equation is valid for all points inside the magnetic field. Thus, the given approximated formula for the field intesity of a point at a distance $\mathrm{d}$ from the phases $\mathrm{A}$ and a (See Figure 4) will be formulated according to equation (10) as:

$\dot{\mathrm{H}}=\dot{\mathrm{I}}_{\mathrm{a}} / 2 \pi \mathrm{d}+\sum_{\mathrm{i}=1}^{\mathrm{n}_{1}}\left(\dot{\mathrm{I}}_{\mathrm{A}} / 2 \pi \mathrm{n}_{1} \mathrm{~d}_{\mathrm{i}}\right)$

where the distance $d_{i} ; i=1-6$; can be evaluated mathematically through the known dimensions $r_{1}$ and $d$. Therefore, the approximated value of field intesity $\mathrm{H}$ may be formulated as

$\dot{\mathrm{H}}=\left(\dot{\mathrm{I}}_{\mathrm{A}} / 2 \pi \mathrm{n}_{1}\right)\left(\mathrm{N} \mathrm{n}_{1} \mathrm{e}^{\mathrm{jQ}} / \mathrm{d}+\sum_{\mathrm{i}=1}^{\mathrm{n}_{1}} 1 / V \mathrm{~d}^{2}+\mathrm{r}_{1}^{2}-2 \mathrm{dr}_{1} \cos \frac{2 \pi(\mathrm{i}-1)}{\mathrm{n}_{1}}\right)$

It should be noted that the conductors $\mathrm{n}_{1}$ of phase $\mathrm{A}$ must be completely transposed as shown in Figure 6 . But this process leads to an equivalent field which will be concentrated at the approximate center of the circle. In this case the total equivalent field intensity may be deduced as

$\dot{\mathrm{H}}=\dot{\mathrm{I}}_{\mathrm{A}}\left(\mathrm{Nn}_{1} \mathrm{e}^{\mathrm{jQ}}+1\right) /\left(2 \pi \mathrm{n}_{1} \mathrm{~d}\right)$

Equation (12) appears to be a special case of equation (11). Therefore, the general formula of equation (12) may be used in order to evaluate the linkage flux $\dot{\psi}$ for the studied transmission line with a length $\ell$. Then, the total flux including internal leakage and external linkage fluxes is defined as

$\dot{\psi}=\int_{-\mathrm{r}_{1}}^{\mathrm{d}} \dot{\mathrm{B}} \mathrm{dz} \ell=\int_{-\mathrm{r}_{1}}^{\mathrm{d}} \mu_{\mathrm{o}} \dot{\mathrm{H}} \mathrm{dz} \ell$ 


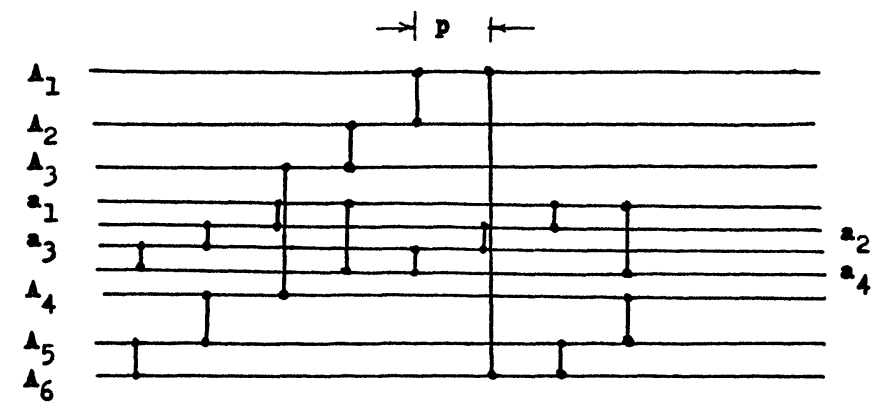

FIGURE 6 The transposition diagram for the conductors of phases of the coaxial type transmission lines.

where $\dot{\mathrm{B}}$ - the flux density

$\mu_{\mathrm{o}}-$ the permeability of free space.

Therefore, the magnetic flux can be finally estimated in the form

$$
\begin{aligned}
\dot{\psi}= & \frac{\ell \mu_{\mathrm{o}} \dot{\mathrm{I}}_{\mathrm{A}}}{2 \pi}\left\{\left(\mathrm{Ne} \mathrm{e}^{\mathrm{jQ}} \ln \mathrm{z}\right)_{\mathrm{r}}^{\mathrm{d}}+\left(1 / \mathrm{n}_{1}\right)\left[\sum _ { \mathrm { i } = 1 } ^ { \mathrm { n } _ { 1 } } \operatorname { l n } \left(2 \gamma / \mathrm{d}^{2}+\mathrm{r}_{1}^{2}-2 \mathrm{dr} \mathrm{r}_{1} \cos \alpha\right.\right.\right. \\
& \left.\left.\left.+2 \mathrm{~d}\left(1-\mathrm{r}_{1} \cos \alpha\right)\right)\right]_{-\mathrm{r} 1}\right\}
\end{aligned}
$$

where $\quad \alpha=2 \pi(\mathrm{i}-1) / \mathrm{n}_{1}$

\section{COUPLING BETWEEN PHASES}

In order to find the mutual inductance $M$ due to linkage flux between the groups of conductors B-b and A-a, integration limits of $S+r_{1}$ and $S+3 r_{1}$ must be inserted. The mutual inductance per unit length may be deduced in the form

$$
\begin{aligned}
\mathrm{M}= & \left(\mu_{\mathrm{o}} / 2 \pi\right)\left(\mathrm{Ne}^{\mathrm{jQ}} \ln [(3+\mathrm{k}) /(1+\mathrm{k})]\right. \\
& \left.+(1 / 6) \ln \frac{(4+\mathrm{k})\left(7+5 \mathrm{k}+\mathrm{k}^{2}\right)\left(13+7 \mathrm{k}+\mathrm{k}^{2}\right)}{\mathrm{k}\left(1+\mathrm{k}+\mathrm{k}^{2}\right)\left(3+3 \mathrm{k}+\mathrm{k}^{2}\right)}\right)
\end{aligned}
$$


where $\mathrm{k}=\mathrm{S} / \mathrm{r}_{1}$

Now, the dependency of mutual inductance between phases should be investigated in detail. However, the value of mutual inductance $M$ is influenced by the ratio between the magnitudes of currents $I_{a} / I_{A}$, where the currents are varying with the change of point of measurement at different conditions of operation (See Figure 5). Also, the mutual inductance depends on the ratio $\mathrm{k}$ as shown from equation (15) so that this ratio may be controlled to get the required spacing. It can be noted that, as concluded previously ${ }^{5}$, the phase angle $\mathrm{Q}$ appears to be constant along all points of a line.

The phase shift between currents appears to be a constant alonge the line and its value will be initially considered as zero. This means that both currents are in phase. In this case, the dependency of mutual inductance between phases A-a and B-b can be estimated. The results of calculations are plotted in Figure 7 at different values

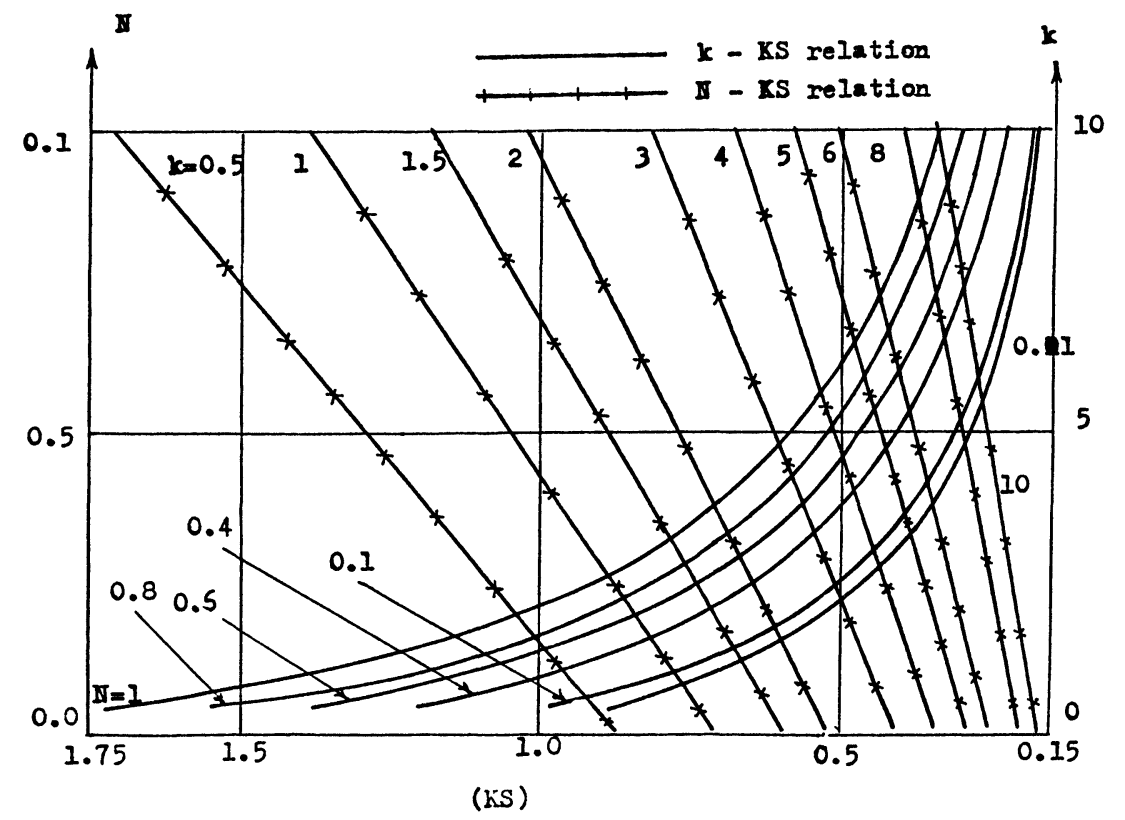

FIGURE 7 The calculated values of coefficient (KS) at zero angle. 
of ratio $\mathrm{k}$ as well as for various ratios of currents N. For small ratios of currents, the results are listed in Table I. For all above results, equation (15) is transformed into a simple formula as

$\mathrm{M}=\left(\mu_{\mathrm{o}} / 2 \pi\right) \mathrm{KS}$

where KS is a computed function while the term $\mu_{\mathrm{o}} / 2 \pi$ is constant. This means that the mutual inductance can be represented through the value $\mathrm{KS}$.

Therefore, the value of mutual inductance is highly dependent on the spacing between the group of conductors of phases A-a and B-b so that the suitable required spacing $S$ can be determined. This effect is given in Table II, which illustrates the percentage decrease in the value of the mutual inductive coupling between groups of phases relative to the base ratio $\mathrm{k}$ of 0.5 at different ratios of currents.

The above calculations are repeated for the condition of $90^{\circ}$ phase shift $\mathrm{Q}$ as shown in Figure 8 . It should be noted that the relation between the ratio $\mathrm{N}$ and the function $\mathrm{KS}$ becomes nonlinear although it is linear for zero phase shift (See Figure 7). This phenomena occurs since the phase angle is contineously changing. Also, the negative angle causes a variation in the direction of $\mathrm{KS}$. The curves in Figure 8 are the absolute values. At a constant ratio of $\mathrm{N}$ in the region of $0.01-0.1$, the computed values of $\mathrm{KS}$ are listed in Table III.

TABLE I

The computed values of the function KS at small ratios of currents (zero phase shift)

\begin{tabular}{ccccc}
\hline $\mathrm{N}$ & 0.01 & 0.05 & 0.08 & 0.10 \\
\hline $\mathrm{k}$ & & & & \\
\hline 0.5 & 0.871 & 0.905 & 0.930 & 0.947 \\
1.0 & 0.702 & 0.730 & 0.750 & 0.764 \\
1.5 & 0.594 & 0.618 & 0.635 & 0.647 \\
2.0 & 0.517 & 0.538 & 0.553 & 0.563 \\
3.0 & 0.409 & 0.426 & 0.438 & 0.446 \\
4.0 & 0.340 & 0.354 & 0.364 & 0.371 \\
5.0 & 0.290 & 0.303 & 0.311 & 0.317 \\
6.0 & 0.255 & 0.265 & 0.272 & 0.277 \\
8.0 & 0.202 & 0.210 & 0.216 & 0.220 \\
10 & 0.169 & 0.176 & 0.181 & 0.184 \\
\hline
\end{tabular}


TABLE II

The percentage decrease in the value of mutual inductance between the nearest groups of phases

\begin{tabular}{rrrrrrr}
\hline \multicolumn{1}{c}{$\mathrm{N}$} & 0.01 & 0.05 & 0.10 & 0.40 & 0.80 & 1.0 \\
$\mathrm{k}$ & & & & & & \\
\hline 1 & 24.4 & 23.9 & 23.9 & 23.8 & 23.4 & 23.6 \\
1.5 & 46.6 & 46.4 & 46.4 & 45.9 & 45.5 & 45.3 \\
2 & 68.5 & 68.2 & 48.2 & 47.9 & 67.6 & 67.5 \\
3 & 112.9 & 112.4 & 111.3 & 110.2 & 110.4 & 110.1 \\
4 & 156.2 & 155.6 & 155.3 & 154.1 & 153.2 & 152.9 \\
5 & 199.3 & 198.7 & 198.7 & 197.5 & 196.5 & 196.2 \\
6 & 241.6 & 241.5 & 241.9 & 241.5 & 241.2 & 241.0 \\
8 & 331.2 & 330.9 & 330.5 & 329.3 & 328.3 & 328.0 \\
10 & 415.4 & 414.2 & 414.7 & 411.5 & 408.9 & 408.0 \\
\hline
\end{tabular}

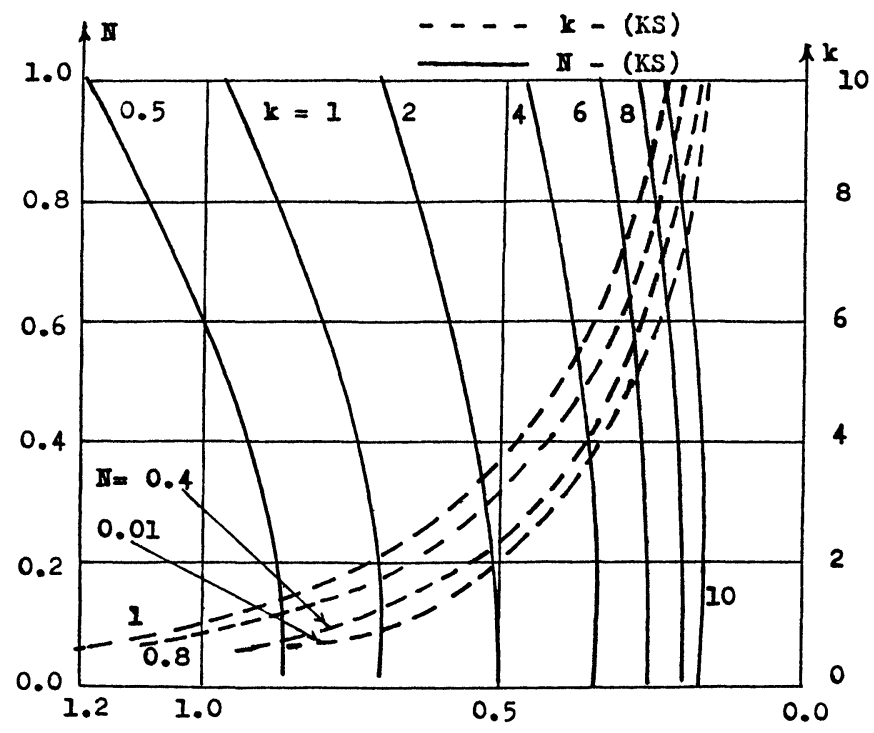

FIGURE 8 The dependency of coefficient KS on factors $\mathrm{k}$ and $\mathrm{N}$ at a constant angle $\mathrm{Q}$ of $90^{\circ}$. 
TABLE III

The calculated function $\mathrm{KS}$ for various ratios $\mathrm{k}$ at a constant angle $\mathrm{Q}$ of $180^{\circ}$

\begin{tabular}{ccccccccc}
\hline $\mathrm{k}$ & 0.5 & 1 & 2 & 3 & 4 & 6 & 8 & 10 \\
$\mathrm{~N}$ & & & & & & & & \\
\hline 0.01 & 0.854 & 0.688 & 0.507 & 0.401 & 0.334 & 0.250 & 0.198 & 0.165 \\
0.10 & 0.777 & 0.626 & 0.461 & 0.364 & 0.303 & 0.227 & 0.180 & 0.150 \\
\hline
\end{tabular}

For a constant phase angle of $180^{\circ}$, the results are plotted in Figure 9. The relation between variable $\mathrm{KS}$ and ratio $\mathrm{N}$ is again linear but with a reverse direction. This may be due to the reverse of the current vector in phase with respect to the other. Also, the curve for the unity current ratio is approximately at the k-axis.

\section{THE EFFECT OF PHASE SHIFT}

The effect of phase shift $\mathrm{Q}$ on the mutual inductance between the two groups is shown in Figure 10-Figure 12. The curves show the

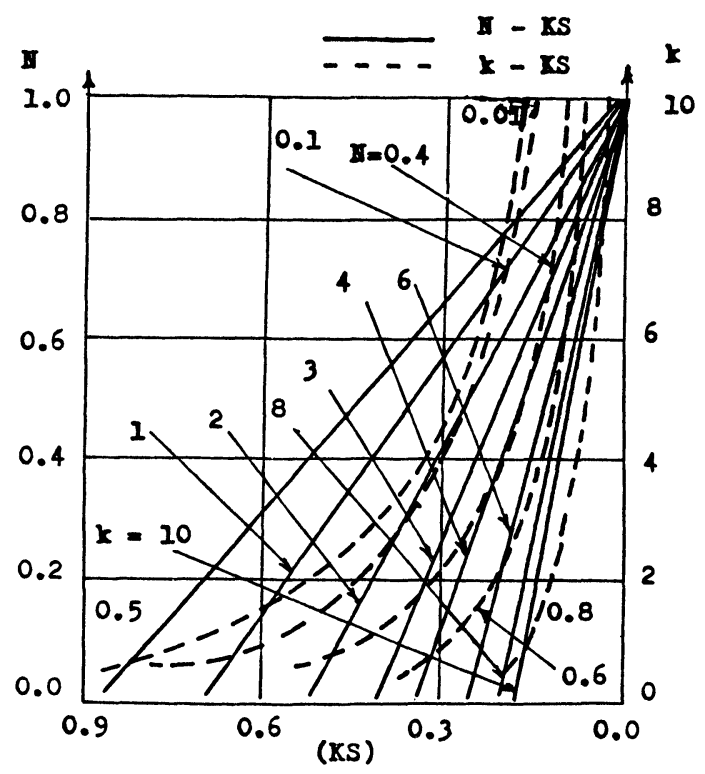

FIGURE 9 The values of KS at a constant phase angle of $180^{\circ}$. 


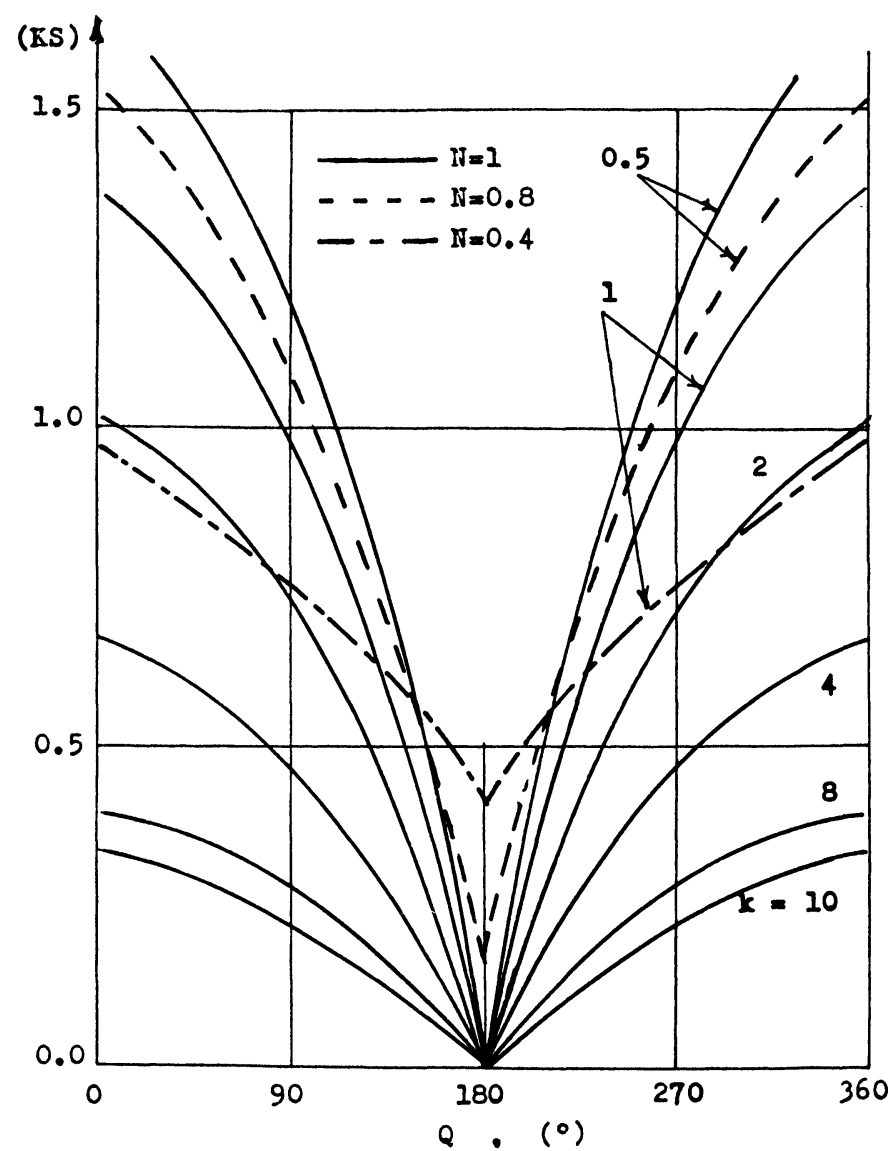

FIGURE 10 The relationship between values of coefficient $\mathrm{KS}$ and factors $\mathrm{k}$ and $\mathrm{Q}$ at different current ratios.

absolute magnitude of the vector KS at different ratios of currents for various values of ratio $\mathrm{k}$. For smaller ratios of currents $(0.01$ and 0.1 ), the calculated absolute values of variable $\mathrm{KS}$ are listed in Table IV.

In Table IV the ratios of currents of 0.01 up to 0.1 approximate straight lines. At large values of ratio of currents $\mathbf{N}$ the curves give more deflection as shown in Figure 10-Figure 12. The ratio of currents cannot reach unity since the current $I_{A}$ appears to be the 


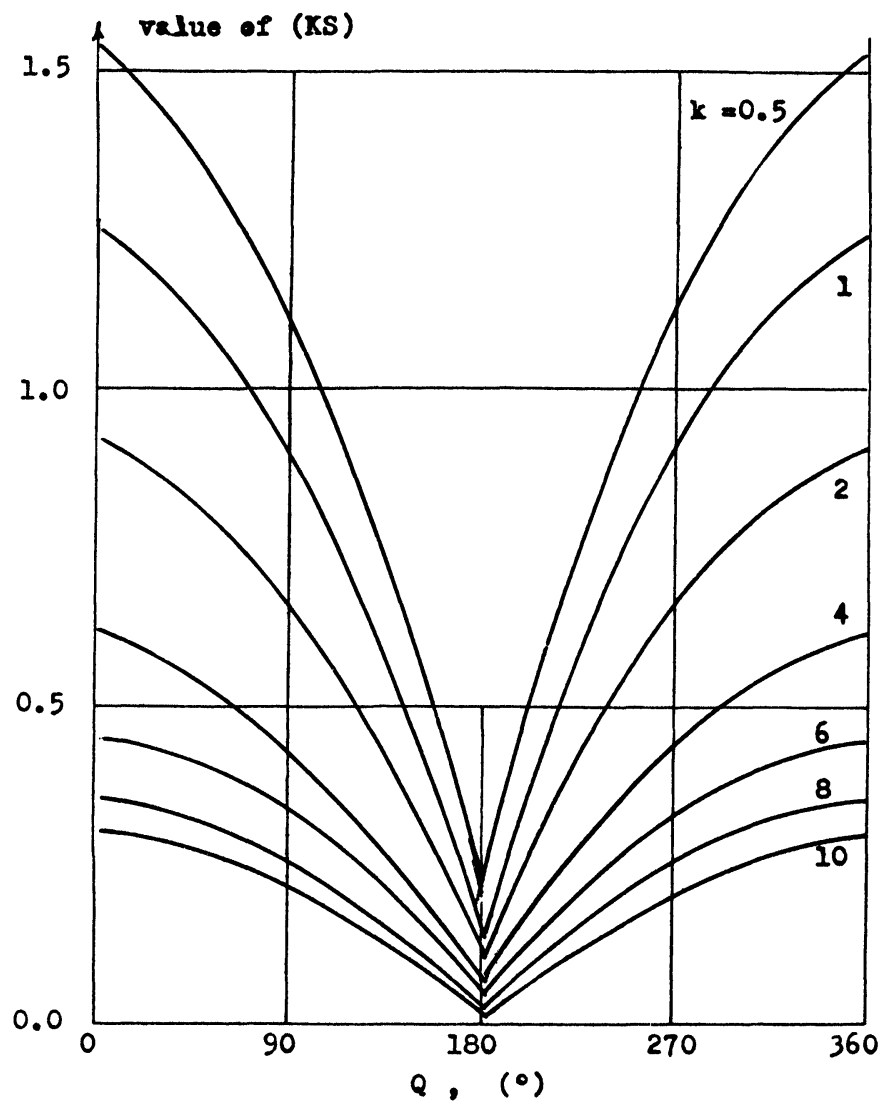

FIGURE 11 The angle characteristics for the coefficient KS at a constant current ratio of 0.8 .

source for the current $I_{a}$. The small ratios of currents mean a degree of mutual coupling, and must be excluded from the practical point of view. Therefore, the suitable values of ratio $\mathrm{N}$ may be in the region of $0.4-0.8$.

It can be concluded that the mutual inductance does not depend upon the phase shift $Q$ at small ratios of currents but is highly depending on phase shift at high ratios $\mathrm{N}$. At an angle of $180^{\circ}$, the mutual inductance is minimum and may be zero. 


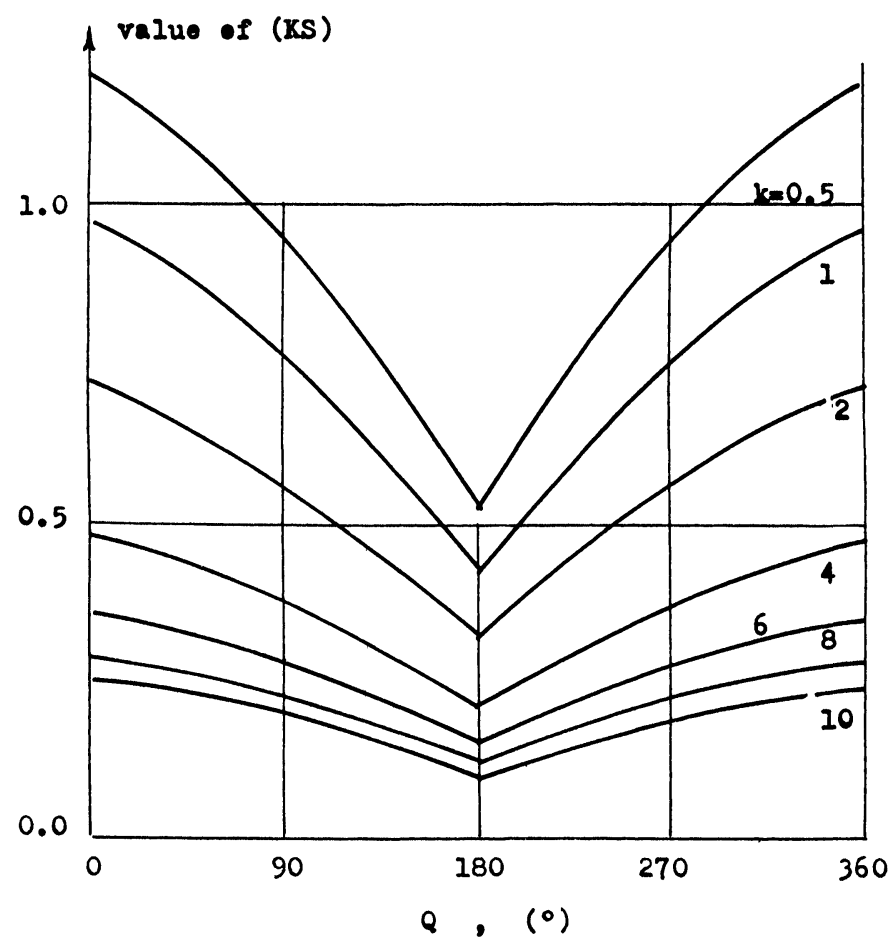

FIGURE 12 The values of $\mathrm{KS}$ at various values of $\mathrm{k}$.

TABLE IV

The calculated values of the vector $\mathrm{KS}$ at different ratios of currents with various ratios $\mathrm{k}$

\begin{tabular}{rrrrrrr}
\hline $\mathrm{N}$ & \multicolumn{2}{c}{0.01} & \multicolumn{5}{c}{0.1} \\
\hline & & & & & \\
$\mathrm{k}$ & $0.0^{\circ}$ & $90^{\circ}$ & $180^{\circ}$ & $0.0^{\circ}$ & $90^{\circ}$ & $180^{\circ}$ \\
\hline 1.5 & & & & & & \\
1.0 & 0.871 & 0.862 & 0.854 & 0.947 & 0.866 & 0.777 \\
2.0 & 0.517 & 0.512 & 0.507 & 0.563 & 0.514 & 0.461 \\
4.0 & 0.340 & 0.338 & 0.334 & 0.371 & 0.339 & 0.303 \\
6.0 & 0.255 & 0.253 & 0.250 & 0.277 & 0.254 & 0.227 \\
8.0 & 0.202 & 0.200 & 0.198 & 0.220 & 0.201 & 0.180 \\
10.0 & 0.169 & 0.167 & 0.165 & 0.184 & 0.168 & 0.150 \\
\hline
\end{tabular}




\section{THE CONTROL OF RATIO OF CURRENTS}

As shown in Figure 5, the current ratio is highly varied and its values become infinity at the receiving end due to zero current $\mathrm{I}_{\mathrm{A}}$ at the noload condition. Thus, a continuously connected impedance must be connected at the receiving end. Using the external capacitance $\mathrm{C}_{\mathrm{ex}}$ at the receiving end the no load zero current will disappear completely. This may modify somewhat the current distribution along the conductor A.

Similarly, an external impedance $Z_{s}$ may be connected at the sending end in order to minimize the variation in current $I_{a}$. Consequently, the ratio of currents $\mathrm{N}$ may be varied in a smaller region so that the proposed line will have the connection shown in Figure 13. Thus, the ratio between currents of both circuits can be controlled.

\section{Connection of Phases}

Since the variation in the mutual inductive coupling between the groups of phases is increased with higher ratio of currents, replacement of the connection for the groups of phases will lead to a significant increase of the ratio of currents $\mathrm{N}$. This ratio should be greater than unity. In this case phase a must be connected to the generator end while phase A will be connected to the load. Therefore, the larger ratio of currents may be introduced in the investigation.

A zero phase shift $\left(\mathrm{Q}=0^{\circ}\right)$ is assumed and the magnitudes of

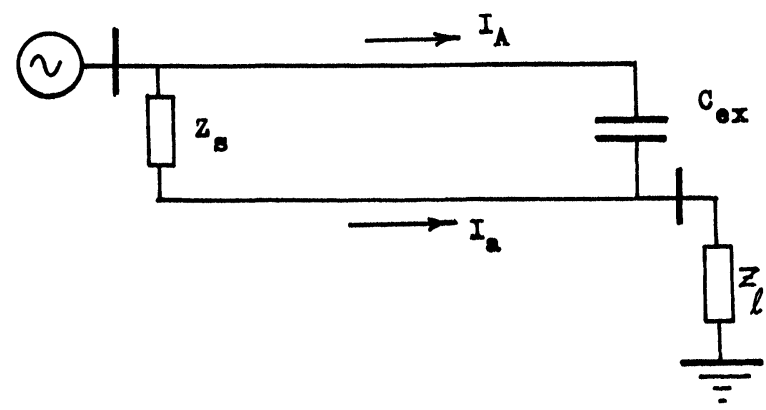

FIGURE 13 The single line diagram for the deduced modified line with limited distribution of current ratio. 
vector $\mathrm{KS}$ are estimated at different values of both ratios of currents $\mathrm{N}$ and distances $\mathrm{k}$. The results are plotted in Figure 14. It is important to mention that the vector KS is still linearly dependent on the ratio of currents $\mathrm{N}$ at constant ratio of distances $\mathrm{k}$. Also, calculations at other values of phase shift are illustrated in Figure 15 and in Figure 16. Two cases as listed in Table V.

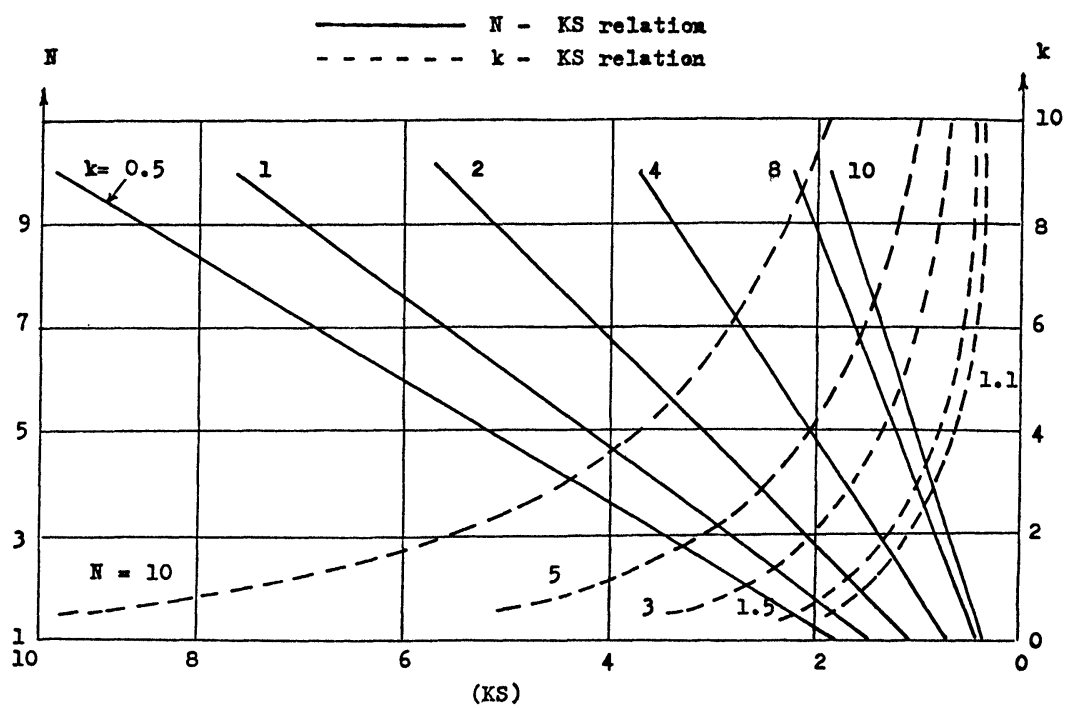

FIGURE 14 The calculated values of the coefficient $\mathrm{KS}$ at zero angle $\mathrm{Q}$ for different current ratios and distances.

TABLE V

The calculated magnitudes of vector KS at different conditions

\begin{tabular}{|c|c|c|c|}
\hline $\begin{array}{l}\text { ratio of } \\
\text { currents } \\
\text { (N) }\end{array}$ & \begin{tabular}{l}
\multicolumn{2}{r}{ ratio of } \\
distances \\
phase (k) \\
shift \\
(Q)
\end{tabular} & 4 & 8 \\
\hline \multirow[t]{3}{*}{4} & $0^{\circ}$ & 1.697 & 1.000 \\
\hline & $90^{\circ}$ & 1.401 & 0.825 \\
\hline & $180^{\circ}$ & 1.023 & 0.600 \\
\hline \multirow[t]{3}{*}{5} & $0^{\circ}$ & 2.037 & 1.200 \\
\hline & $90^{\circ}$ & 1.733 & 1.020 \\
\hline & $180^{\circ}$ & 1.363 & 0.800 \\
\hline
\end{tabular}


COUPLING BETWEEN SEPARATE PHASES OF COAXIAL DOUBLE CIRCUIT 105

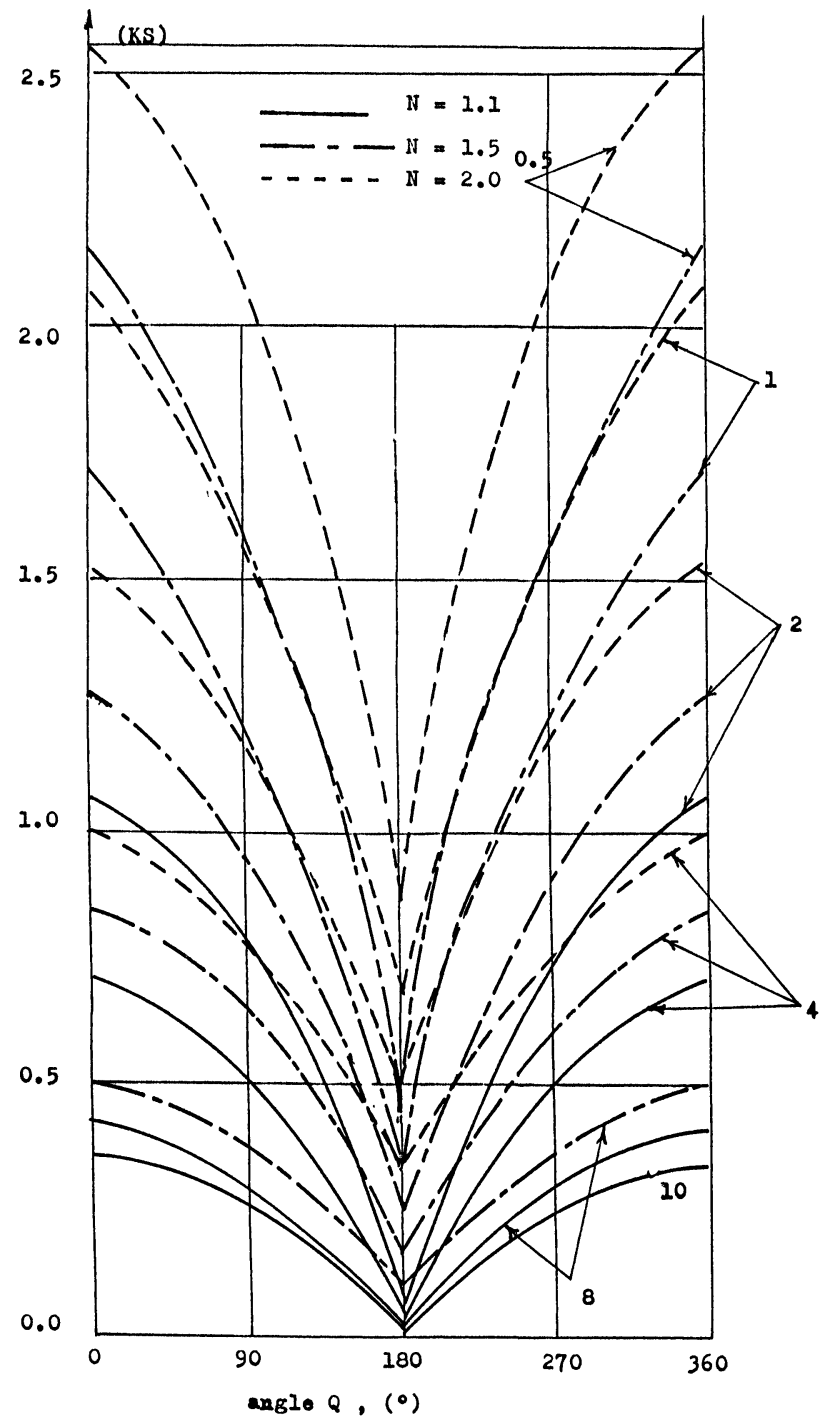

FIGURE 15 The dependency of values KS on the variation of angle Q. 


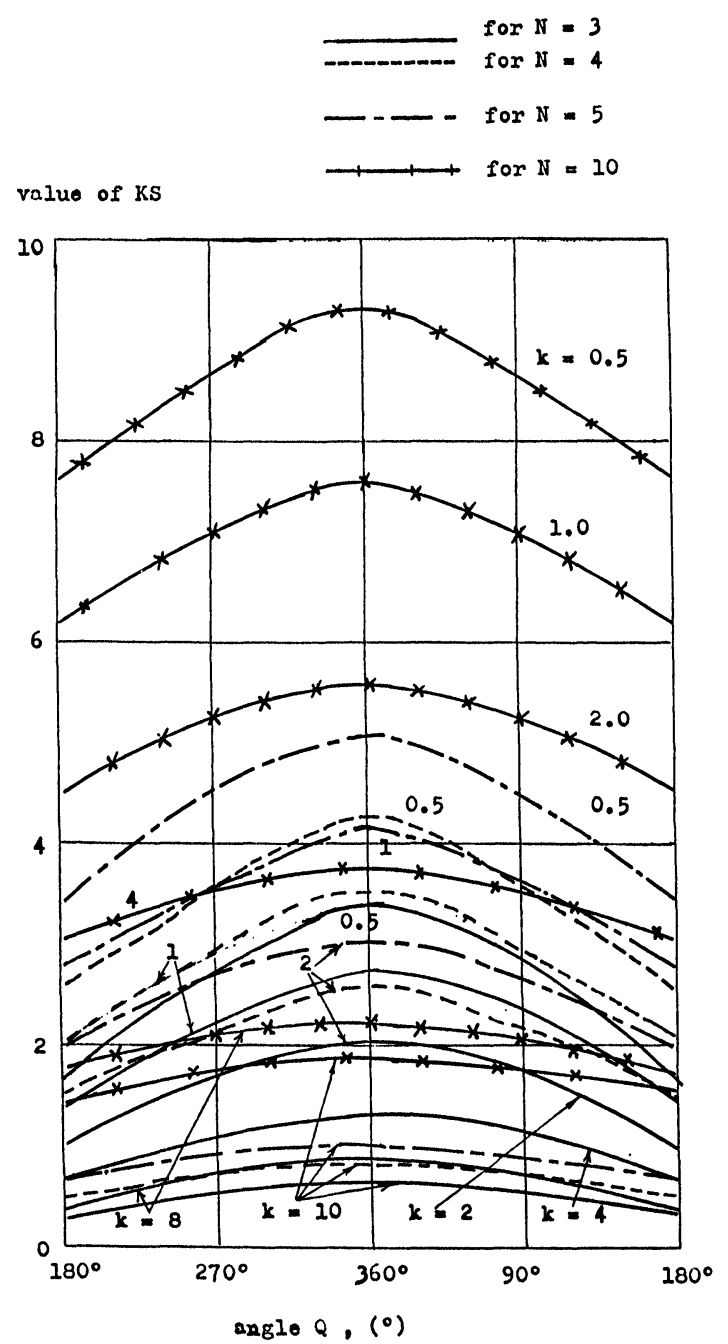

FIGURE 16 The calculated coefficient KS with the variation of angle $\mathrm{Q}$ at different values of current ratios. 
From the above study it can be seen from Figures 15, 16 and Table V that:

1. the mutual coupling is still minimum at phase shift of $180^{\circ}$ for each constant ratio of distances $\mathrm{k}$;

2. the inductive coupling is increased with the decrease in the ratio of distances $\mathrm{k}$;

3 . the coupling at ratio of currents more than unity is greater than that at ratio of currents less than unity;

4. at large ratios of distances $\mathrm{k}$, the minimum coupling with zero angle of phase shift is slowly moved. It can be considered as a constant.

5. the same value of coupling is depending on the ratio of currents $\mathrm{N}$ as well as on the ratio of distances $\mathrm{k}$ and on the phase shift between both currents in the same moment.

Practically, the phase shift may be varied around $90^{\circ}$ since the coupling is achieved using the reactive mutual effect. This means that the connection condition of $90^{\circ}$ phase shift appears to be more practicable.

\section{CONCLUSIONS}

The mutual coupling between phases of coaxial overhead transmission lines is constant at small ratios of currents and independent on the phase shift between currents. The mutual coupling between groups of phases is highly varied with the change in the phase shift between the currents at large ratios of currents.

The mutual inductance between groups of phases of coaxial lines is highly increased with the increase of current ratio.

The ratio of currents may be controlled by using the compensating impedances at both ends of the double circuit transmission lines so that the mutual inductance between phases can be controlled.

The mutual coupling between groups of phases depends on the ratio of currents, ratio of distances, and on the phase shift between currents. 


\section{APPENDIX $^{10}$ The Mathematical Analysis}

As the spacing of the conductors is symmetrical and the phase voltages applied to conductors $\mathrm{A}, \mathrm{B}$, and $\mathrm{C}$ are balanced, the relation between the charges $\mathrm{Q}$ on the conductors and the voltages $\mathrm{V}$ applied to the conductors is given by

$V_{A}=2 Q_{A} \operatorname{Ln}\left(\frac{\sqrt{3 d}}{r}\right)-2 Q_{a} \operatorname{Ln} 2$

$\mathrm{V}_{\mathrm{a}}=-2 \mathrm{Q}_{\mathrm{A}} \operatorname{Ln} 2+2 \mathrm{Q}_{\mathrm{a}} \operatorname{Ln}\left(\frac{\sqrt{ } 3 \mathrm{~d}}{\mathrm{r}}\right)$

where $\mathrm{d}$ is the distance between adjacent conductors and $\mathrm{r}$ is the radius of the conductors.

From equations (1), the following equations can be deduced:

$$
\begin{aligned}
& \frac{\mathrm{di}_{\mathrm{A}}}{\mathrm{dx}}=-\mathrm{Y}_{\mathrm{S}} \mathrm{V}_{\mathrm{A}}-\mathrm{Y}_{\mathrm{m}} \mathrm{V}_{\mathrm{a}} \\
& \frac{\mathrm{di}_{\mathrm{a}}}{\mathrm{dx}}=-\mathrm{Y}_{\mathrm{s}} \mathrm{V}_{\mathrm{a}}-\mathrm{Y}_{\mathrm{m}} \mathrm{V}_{\mathrm{A}} \\
& \frac{\mathrm{dV} \mathrm{A}}{\mathrm{dx}}=-\mathrm{Z}_{\mathrm{s}} \mathrm{i}_{\mathrm{A}}-\mathrm{Z}_{\mathrm{m}} \mathrm{i}_{\mathrm{a}} \\
& \frac{\mathrm{dV_{ \textrm {a } }}}{\mathrm{dx}}=-Z_{\mathrm{s}} \mathrm{i}_{\mathrm{a}}-Z_{\mathrm{m}} \mathrm{i}_{\mathrm{A}}
\end{aligned}
$$

where the self and mutual admittances $Y_{s}$ and $Y_{m}$ and the self and mutual impedances $Z_{\mathrm{s}}$ and $\mathrm{Z}_{\mathrm{m}}$ of the line can be computed.

Differentiating equations (2) with respect to $\mathrm{x}$ and then differentiating again twice more, we have

$$
\frac{d^{4} V_{A}}{d x^{4}}-2 a_{s}^{2} \frac{d^{2} V_{A}}{d x^{2}}-V_{A}\left(a_{m}^{4}-a_{s}^{4}\right)=0
$$

Equation (3) has the general solution: 
$V_{A}(x)=A \cdot \cosh a_{1} x+B \cdot \sinh a_{1} x+C \cdot \cosh a_{2} x+D \cdot \sinh a_{2} x$

$V_{a}(x)=A \cdot \cosh a_{1} x+B \cdot \sinh a_{1} x-C \cdot \cosh a_{2} x-D \cdot \sinh a_{2} x$

where the first and second propagation coefficients $a_{1} a$ and $a_{2}$ are given in the form

$\mathrm{a}_{1}=V \mathrm{a}_{\mathrm{s}}^{2}+\mathrm{a}_{\mathrm{m}}^{2}$ and $\mathrm{a}_{2}=V \mathrm{a}_{\mathrm{s}}^{2}-\mathrm{a}_{\mathrm{m}}^{2}$

Integrating equations (2), the current at a point $\mathrm{x}$ of the line will be

$i_{a}(x)=-\frac{A}{a_{1}} y_{1} \sinh a_{1} x-\frac{B y_{1}}{a_{1}} \cosh a_{1} x+\frac{C y_{2}}{a_{2}} \sinh a_{2} x+\frac{D y_{2}}{a_{2}} \cosh$

$i_{A}(x)=-\frac{A y_{1}}{a_{1}} \sinh a_{1} x+\frac{B y_{1}}{a_{1}} \cosh a_{1} x-\frac{C y_{2}}{a_{2}} \sinh a_{2} x-\frac{D y_{2}}{a_{2}} \cosh a_{2} x$

where $y_{1}=Y_{s}+Y_{m}$ and $y_{2}=Y_{s}-Y_{m}$

These equations (4) and (5) are the general equations for the suggested coaxial transmission line. Only the constants A, B, C, and $\mathrm{D}$ are unknown, since all the other constants can be determined from the parameters of the transmission line.

In order to express the general equations in terms of the parameters of the circuit, the generator voltage $V_{G}$ and the generator current $I_{G}$ only, the constants $A, B, C$, and $D$ in these terms must be computed using the terminal conditions.

As we have all the four constants expressed in terms of the generator-voltage and current and the parameters of the transmission line, then using equation (4) for voltages $\mathrm{V}_{\mathrm{A}}$ and $\mathrm{V}_{\mathrm{a}}$ and equation (5) for currents $I_{A}$ and $i_{a}$, the general equations for the coaxial lines can be obtained in the final form as: 


$$
\begin{aligned}
& V_{A}(x)=A \cdot \cosh a_{1} x+C \cdot \cosh a_{2} x-\frac{I_{G}}{2}\left(\frac{a_{1}}{y_{1}} \cdot \sinh a_{1} x+\frac{a_{2}}{y_{2}} \cdot \sinh a_{2} x\right) \\
& V_{a}(x)=A \cdot \cosh a_{1} x-C \cdot \cosh a_{2} x-\frac{I_{G}}{2}\left(\frac{a_{1}}{y_{1}} \cdot \sinh a_{1} x-\frac{a_{2}}{y_{2}} \cdot \sinh a_{2} x\right) \\
& I_{A}(x)=-\frac{A}{a_{1}} \cdot y_{1} \cdot \sinh a_{1} x-\frac{C}{a_{2}} \cdot y_{2} \cdot \sinh a_{2} x+\frac{I_{G}}{2} m_{1} \\
& i_{a}(x)=-\frac{A}{a_{1}} \cdot y_{1} \cdot \sinh a_{1} x+\frac{C}{a_{2}} \cdot y_{2} \cdot \sinh a_{2} x+\frac{I_{G}}{2} m_{3}
\end{aligned}
$$


COUPLING BETWEEN SEPARATE PHASES OF COAXIAL DOUBLE CIRCUIT 111

\section{REFERENCES}

1. F.J. Ellert et al.: UHV power transmission. Electra, France, Dec., (1980) 21-68.

2. M. Hamed: The electrical performance of the controlled type transmission lines. Proc. of the 27-th Midwest Symposium on Circuits and Systems. Morgantown, USA, June 11-12, vol. 1, (1984) 399-402.

3. G.N. Alexandrov and G.V. Podporkyn: Control of the electric strength of long air gaps. IEEE Trans., vol. PAS-101, (1982) 4395-4398.

4. G.N. Alexandrov and G.V. Podporkyn: Investigation of the line influence of the conductor configuration on the electric strength of air gaps between conductor and ground. Electritchestvo, USSR, No. 3, (1977) 62-64.

5. M. Hamed and S. El Dessouky: Coaxial overhead transmission line performance. Proc. of the 27-th Midwest Symposium on Circuits and Systems, Morgantown, USA, June 11-12, vol. 1, (1984) 338-340.

6. M. Hamed: The steady state characteristics of the radial type transmission line. Proc. of JIEEEC'85, 28 April-1 May, Amman, Jordan, (1985) 425-429.

7. E.W. Kimbark: A new look at shunt compensation. IEEE Trans., vol. PAS-102, No. 1, (1983) 212-218.

8. M. Hamed: The electrical performance of ring type transmission lines. Proc. of the IASTED Inter. Con. EES'84, Nice, France, June 19-21, (1984) 102-105.

9. M. Hamed: On the possibility of transient calculations in single circuit untransposed transmission lines using Laplace transforms. Proc. of JIEEEC, Amman, Jordan, vol. 1, (1983) 39-43.

10. M. Hamed \& S.S. EL Dessouky: On the possibility of power transmission through coaxial overhead transmission lines. Journal of the Egyptian Society of Engineers, vol. 23, No. 2, (1984) 30-38.

11. G.N. Alexandrov: Overhead transmission lines with heavy carrying capacity. Electritchestvo, USSR, No. 7, (1981) 1-6.

12. J.R. Stewart and D.D. Wilson: High phase order transmission-a feasibility analysis part I-steady state considerations, and part II-over-voltages and insulation requirements. IEEE Trans., vol. PAS-97, (1978) 2300-2317. 

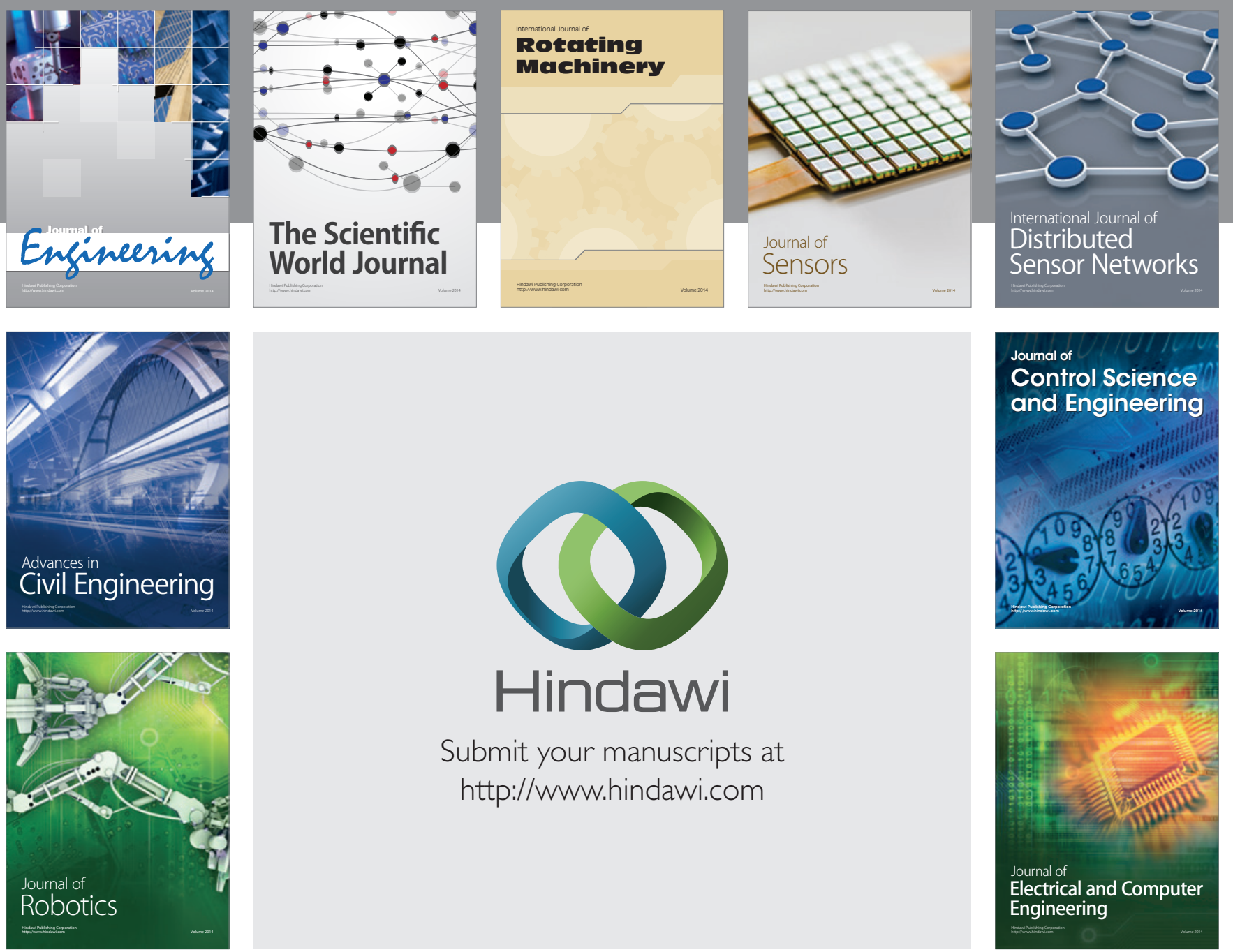

Submit your manuscripts at

http://www.hindawi.com
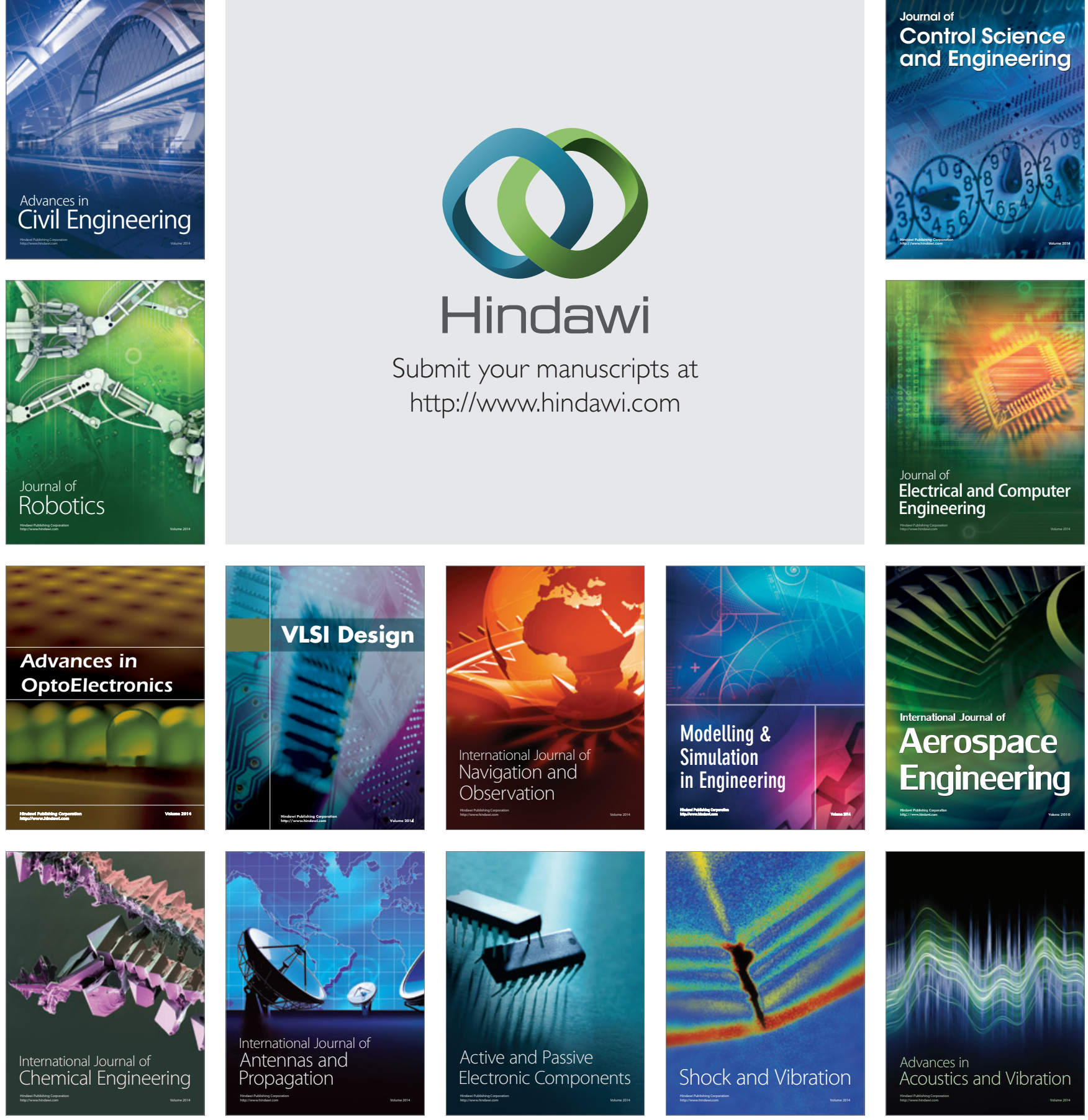